\title{
Sphingosine 1-phosphate axis: a new leader actor in skeletal muscle biology
}

\author{
Chiara Donati ${ }^{1,2}$, Francesca Cencetti ${ }^{1,2}$ and Paola Bruni ${ }^{1,2 *}$ \\ ${ }^{1}$ Dipartimento di Scienze Biomediche, Sperimentali e Cliniche, University of Florence, Florence, Italy \\ 2 Istituto Interuniversitario di Miologia, Italy
}

\section{Edited by:}

Lucas Guimarães-Ferreira, Federal

University of Espirito Santo, Brazil

Reviewed by:

Leonardo F. Ferreira, University of

Florida, USA

Adam Philip Sharples, Liverpool

John Moores University, UK

*Correspondence:

Paola Bruni, Dipartimento di Scienze Biomediche, Sperimentali e Cliniche,

Viale GB Morgagni 50,

50134 Florence, Italy

e-mail: paola.bruni@unifi.it
Sphingosine 1-phosphate (S1P) is a bioactive lipid involved in the regulation of biological processes such as proliferation, differentiation, motility, and survival. Here we review the role of S1P in the biology and homeostasis of skeletal muscle. S1P derives from the catabolism of sphingomyelin and is produced by sphingosine phosphorylation catalyzed by sphingosine kinase (SK). S1P can act either intracellularly or extracellularly through specific ligation to its five G protein-coupled receptors (GPCR) named S1P receptors (S1PR). Many experimental findings obtained in the last 20 years demonstrate that S1P and its metabolism play a multifaceted role in the regulation of skeletal muscle regeneration. Indeed, this lipid is known to activate muscle-resident satellite cells, regulating their proliferation and differentiation, as well as mesenchymal progenitors such as mesoangioblasts that originate outside skeletal muscle, both involved in tissue repair following an injury or disease. The molecular mechanism of action of S1P in skeletal muscle cell precursors is highly complex, especially because S1P axis is under the control of a number of growth factors and cytokines, canonical regulators of skeletal muscle biology. Moreover, this lipid is crucially involved in the regulation of skeletal muscle contractile properties, responsiveness to insulin, fatigue resistance and tropism. Overall, on the basis of these findings S1P signaling appears to be an appealing pharmacological target for improving skeletal muscle repair. Nevertheless, further understanding is required on the regulation of S1P downstream signaling pathways and the expression of S1PR. This article will resume our current knowledge on S1P signaling in skeletal muscle, hopefully stimulating further investigation in the field, aimed at individuating novel molecular targets for ameliorating skeletal muscle regeneration and reducing fibrosis of the tissue after a trauma or due to skeletal muscle diseases.

Keywords: sphingosine 1-phosphate, skeletal muscle, skeletal muscle progenitors, satellite cells, muscle regeneration, insulin responsiveness, myoblasts, skeletal muscle metabolism

\section{INTRODUCTION ON SKELETAL MUSCLE}

Skeletal muscle represents about $40 \%$ of the entire body weight. The functional and structural constituent of skeletal muscle is the myofiber, multinucleated cell that derives from the fusion of mesodermal precursors named myoblasts. Each myofiber is delimited by the basal lamina and is composed of myofibrils of actin and myosin, organized as a sarcomere, the functional unit of skeletal muscle. On the basis of their physiological features, muscle fibers can be distinguished into slow contracting, fatigue resistant fibers and fast contracting, fatigue sensitive fibers.

Skeletal muscle exerts physiological roles relevant for the control of body metabolism since it accounts for bloodstream aminoacid disposal in fasting condition and for removing excess glucose by favoring glycogen accumulation in response to insulin after a meal. Moreover, by releasing heat during force generation it contributes to body temperature maintenance.

During development, the number of myofibers following myoblast fusion increase, while in adulthood skeletal muscle is stable beyond infrequent fusion of satellite cells to compensate physiologic turnover. Following a trauma, injury, or disease skeletal muscle has indeed the potential to regenerate thanks to an highly orchestrated process driven by satellite cells and their niche (Yin et al., 2013).

Satellite cells are the resident stem cells of the skeletal muscle, located between the basal lamina of muscle fibers and the plasma membrane. Even if it is known that satellite cells derive from somites, their exact progenitor cell is still elusive. Satellite cells are quiescent in adult skeletal muscle and represent 3-6\% of the total nuclei in the fiber (Tedesco et al., 2010). When activated, they start proliferating and can generate in few days a large number of myofibers: it has been demonstrated that few as seven satellite cells transplanted into irradiated muscle of dystrophic immune-deficient mice led to an increase of 100 new muscle fibers with thousands of myonuclei (Collins et al., 2005). Activated satellite cells cultured on plastic collagen-coated dishes are named "satellite cell-derived myoblasts" or myogenic precursor cells distinct from a functional and molecular point of view from freshly isolated satellite cells, possibly due to the absence of their niche (Dhawan and Rando, 2005; Pallafacchina et al., 2010). Stem cells can self-renew in asymmetric and symmetric 
division. In asymmetric division the parental stem cell divides into two different daughter cells, one remains stem cell, the other fated to differentiate. In symmetric division the parental stem cell gives rise to two daughter stem cells of equal stemness. Satellite cells can undergo asymmetric and symmetric division and non-canonical Wnt signaling plays a role in the regulation of self-renewal (Chargé and Rudnicki, 2004; Troy et al., 2012). A number of satellite cell markers have been identified such as Pax3, Pax7, Myf5, M-cadherin, cMet, CD34, CXCR4, although they are not unique and there is not complete correspondence between mouse and human (Yin et al., 2013).

In addition to satellite cells, other skeletal muscle progenitors including pericytes (Dellavalle et al., 2011), mesoangioblasts (Minasi et al., 2002), bone marrow stem cells (LaBarge and Blau, 2002), and interstitial cells (Mitchell et al., 2010) located outside the myofiber, have been demonstrated to have the ability to regenerate skeletal muscle, although to a negligible extent compared with satellite cells (Judson et al., 2013). Nowadays there is a great interest in understanding the molecular mechanisms of skeletal muscle regeneration since it will permit the development of cell therapies for skeletal muscle diseases such as muscular dystrophies (Tedesco et al., 2010), a group of inherited disorders characterized by progressive muscle wasting and depletion of the satellite cell pool after extensive cycle of regeneration (Carlson and Conboy, 2007; Chakkalakal et al., 2012; Pannérec et al., 2012; García-Prat et al., 2013). Muscular dystrophies are indeed very difficult to treat because skeletal muscle is composed of hundreds of millions of post-mitotic nuclei.

\section{SPHINGOLIPID METABOLISM AND SPHINGOSINE 1-PHOSPHATE FORMATION}

During the last 20 years, sphingolipids, initially considered structural component of eukaryotic membranes, have been highlighted as a crucial molecules involved in the regulation of fundamental biological processes such as cell migration, survival, proliferation, differentiation, adhesion, and implicated in inflammation, tumorigenesis, immunity and vascular development (Hannun and Obeid, 2008; Maceyka et al., 2012). In this review we will focus on the role of the bioactive sphingolipid sphingosine 1-phosphate (S1P), its metabolism, its receptors and its cross-talk with growth factors and cytokines in skeletal muscle biology and physiology.

Ceramide, a largely known effector of stress responses (Zeidan and Hannun, 2010) plays a central role in sphingolipid metabolism. The first step in the de novo pathway of ceramide production is the condensation reaction catalyzed by the enzyme serine palmitoyl transferase to form dihydrosphingosine from palmitoyl-CoA and the aminoacid serine. Dihydrosphingosine is then acylated by the action of ceramide synthase to dihydroceramide which is then desaturated to ceramide by the enzyme ceramide desaturase. Ceramide can be also generated by the breakdown of membrane sphingomyelins, catalyzed by the action of various sphingomyelinases or by the degradation of complex glycosphingolipids by the action of glucosylceramidases. The acyl chain of ceramide is then removed by the action of ceramidases and the amino alcohol sphingosine is produced. Sphingosine can be reconverted to ceramide by the action of ceramide synthase via the so-called salvage pathway mechanism. Sphingosine can be phosphorylated in an ATP-dependent manner to S1P by the enzymes sphingosine kinase (SK) 1 and SK2. S1P can be dephosphorylated back to sphingosine by the action of two specific S1P phosphatases and by three lipid phosphate phosphatases. Alternatively, S1P is irreversibly degraded by the action of S1P lyase (SPL) into hexadecenal and phosphoethanolamine.

SK1 is a cytosolic enzyme which contains residues that bind acidic phospholipids that contribute to its intracellular localization (Stahelin et al., 2005). Numerous agonists have been reported to be able to activate SK1, including growth factors, hormones, cytokines, and G protein-coupled receptors (GPCR) ligands. Following ERK phosphorylation at serine 225, SK1 translocates to plasma membrane where its substrate sphingosine is localized (Pitson et al., 2003). The regulation of SK localization within the cell is the major mechanism by which the enzyme affects sphingolipid metabolism since only minute increases in the activity are reported following stimulation with different agonists. Once produced, $\mathrm{S} 1 \mathrm{P}$, precisely partitioned into plasma membrane microdomains, is then locally released to activate S1P receptors (S1PR) acting in autocrine and/or paracrine manner. This process is called "inside-out" signaling. Different transporters have been implicated in S1P export such as the ATP binding cassette transporters, ABCC1 (Mitra et al., 2006), ABCA1 (Sato et al., 2007), ABCG2 (Takabe et al., 2010), and more recently the specific spinster 2 (Spns2) (Kawahara et al., 2009); however, no information on their role in skeletal muscle is presently available. Additionally, since the chloride ion channel CFTR has a role in mediating S1P transport and signaling in heart (Meissner et al., 2012) and lack of CFTR causes functional alteration in skeletal muscle (Divangahi et al., 2009), it will be of interest to further investigate this issue.

In contrast to SK1, SK2 is localized in several intracellular compartments such as endoplasmic reticulum, nucleus, and mitochondria. Even if it is known that ERK-mediated phosphorylation is required for SK2 activation, the exact mechanism of SK2 regulation is still elusive. While SK1-formed S1P is rapidly exported outside the cell through the transporters localized at the plasma membrane, SK2-produced S1P at the level of mitochondria and endoplasmic reticulum is likely rapidly degraded or dephosphorylated by SPL and phosphatases present in close proximity. Therefore, SK2 has, in respect to SK1, an enhanced ability to recycle sphingoid bases for ceramide synthesis (Le Stunff et al., 2007). Compared to SK1, less is known about the mechanism of SK2 regulation. It has been reported that EGF and phorbol ester (Hait et al., 2007) activates the enzyme. Moreover, under hypoxia an increase in SK2 protein level and enzymatic activity has been demonstrated (Schnitzer et al., 2009).

Bioactive S1P can either function as ligand of a family of GPCR named S1PR and through intracellular targets, some of them recently identified. There are five specific $S 1 P R, S 1 P R_{1-5}$, all with low nM Kd values. Since these receptors couple to multiple $\alpha$ subunits of heterotrimeric $\mathrm{G}$ proteins and are differentially expressed in diverse cell types and tissues, they induce the activation of different downstream targets such as ERK, Rac, Rho, JNK, adenylyl cyclase, phospholipase $\mathrm{C}$, thus evoking distinct, sometimes overlapping or opposite, biological responses. While $\mathrm{S}_{1-3}$ are ubiquitously expressed, $\mathrm{S}_{4} \mathrm{P}_{4}$ and $\mathrm{S}_{1} \mathrm{P}_{5}$ are tissue specific, being 
mostly expressed in the lymphoid and central nervous system, respectively (Spiegel and Milstien, 2003). S1P 1 plays a crucial role in angiogenesis, indeed its deletion in mice is embryonic lethal due to hemorrhage for incomplete vascular maturation since pericytes do not migrate to the nascent endothelial tubes (Liu et al., 2000). $S 1 P_{2}$ null mice are deaf indicating that $S 1 P_{2}$ is required for proper development of the auditory and vestibular systems (Kono et al., 2007). Unlike $S 1 P_{1}$ null mice, $\mathrm{S}_{1} \mathrm{P}_{3}$ deletion in mice do not generate any obvious phenotype.

A number of cytokines and growth factors have been reported to regulate the expression of the enzymes of S1P metabolism (Lebman and Spiegel, 2008). In addition to S1PR transactivation following stimulation with growth factors and cytokines, S1P ligation to its receptors also transactivates growth factor tyrosine kinase receptors. This mutual functional cross-talk regulates fundamental biological processes such as growth, differentiation, and motility in various cell types.

Many data reported in literature support that the intracellular role of $\mathrm{S} 1 \mathrm{P}$ is that of counteracting the biological actions of ceramide in the so-called "rheostat model" where the S1Pforming enzyme SK plays a crucial role. Although S1P was discovered as intracellular messenger (Olivera and Spiegel, 1993), only recently, some of the intracellular targets of S1P have begun to be identified. SK2 present in the nucleus has been demonstrated to form a complex with histone $\mathrm{H} 3$ and histone deacetylases (HDACs). SK2-produced S1P binds to and inhibits HDAC1/2, thus contributing to the regulation of the epigenetic control of specific genes (Hait et al., 2009). Instead, tumor necrosis factor receptor associated factor 2 (TRAF2), a crucial component in $\mathrm{NFkB}$ signaling triggered by $\mathrm{TNF} \alpha$, has been reported as intracellular target for S1P produced by SK1. Indeed, S1P formed by SK1, which is known to co-localize with TRAF2 (Xia et al., 2002) has been found to bind to TRAF2 and stimulate its dormant ubiquitin ligase activity upstream of NFkB activation (Alvarez et al., 2010). Moreover, SK2-produced S1P in the mitochondrion binds in vitro and in vivo to prohibitin 2, a conserved protein that regulates mitochondrial assembly and function. SK2 null mice display reduced mitochondria respiration, suggesting that $\mathrm{S} 1 \mathrm{P} /$ prohibitin 2 interaction is physiologically relevant for mitochondrial function (Strub et al., 2011).

\section{BIOLOGICAL ROLE OF S1P IN SATELLITE CELLS}

A number of recently published papers support the role of S1P axis in the regulation of muscle resident satellite cell biology. Indeed, S1P was identified as one of the few extracellular cues capable of stimulating quiescent satellite cells to enter the cell cycle (Nagata et al., 2006). Inhibition of S1P formation by incubation with the SK inhibitor dimethylsphingosine (DMS) significantly reduced satellite cell activation in response to mitogen and impaired satellite cell-driven muscle regeneration in response to in vivo damage induced by cardiotoxin. Moreover, the authors showed that the degradation of the sphingomyelin inner leaflet pool accounts for the generation of S1P, then regulating satellite cell activation. In line with these findings, Calise et al. have characterized the S1PR involved in the mitogenic effect of S1P and the underlying mechanism of action (Calise et al., 2012). Satellite cells express 4 out of $5 \mathrm{~S} 1 \mathrm{PR}, \mathrm{S}_{\mathrm{PR}_{1-4}}$, being $\mathrm{S}_{1} \mathrm{P}_{3}$ the most expressed one in growing conditions. Indeed, by utilizing specific receptor antagonist and siRNA silencing, S1P was demonstrated to stimulate labeled thymidine incorporation by engagement of $\mathrm{S}_{2} \mathrm{P}_{2}$ and $\mathrm{S}_{1} \mathrm{P}_{3}$ in a $\mathrm{PI} 3 \mathrm{~K}$-dependent manner. Moreover, the authors demonstrated also that S1P positively stimulates satellite cell migration via specific ligation to $\mathrm{S}_{1} \mathrm{P}_{1}$ and $\mathrm{S}_{1} \mathrm{P}_{4}$. This latter finding, for the first time, highlights the role of $\mathrm{S}_{\mathrm{P}} \mathrm{P}_{4}$ in skeletal muscle beyond its already established relevance in lymphoid tissue. Very recently it has been shown that $\mathrm{S}_{3} \mathrm{P}_{3}$ suppresses cell cycle progression in murine satellite cells (Fortier et al., 2013). Indeed, satellite cells isolated from $\mathrm{S}_{3}$ null mice showed enhanced ex-vivo proliferation, while retrovirally-mediated constitutive expression of $\mathrm{S} \mathrm{P}_{3}$ inhibited cell proliferation of satellite cells.

\section{BIOLOGICAL ROLE OF S1P IN OTHER SKELETAL MUSCLE PROGENITORS}

Skeletal muscle regeneration, besides being due to the presence of resident satellite cells in skeletal muscle, is carried on, in vivo or after transplantation, by progenitors that originates outside the basal lamina such as pericytes, interstitial cells, mesoangioblasts, and adipose tissue-derived mesenchymal stem cells (ASC). The characterization of the molecular mechanism of the myogenic potential of these progenitors is nowadays of great interest since such kind of knowledge could be applied in the development of cell therapies for diseases characterized by skeletal muscle degeneration. S1P axis has been shown to play a role in the regulation of fundamental biological parameters such as proliferation, migration and differentiation of multipotent adult stem cells such as mesoangioblasts (Donati et al., 2007a, 2009, 2011), and ASC (Nincheri et al., 2009).

Mesoangioblasts (Minasi et al., 2002) are vascular progenitors associated with dorsal aorta in avian and mammalian species, that when transplanted in vivo give rise to multiple mesodermal cell types such as osteoblasts, chondrocytes, and muscle cells. They show an extensive ability of in vitro self-renewing and upon injection, are able to cross the endothelial barrier and can fuse with muscle fibers, contributing to their regeneration. Indeed, mesoangioblasts have been demonstrated to contribute to muscle regeneration in animal models of muscular dystrophy such as $\alpha$-sarcoglycan null mice (Sampaolesi et al., 2003) and golden retriever dystrophic dogs (Sampaolesi et al., 2006). S1P $P_{1-3}$ were detected at mRNA level in mesoangioblasts with $\mathrm{S}_{1} \mathrm{P}_{3}$ the predominantly expressed receptor. $\mathrm{S} 1 \mathrm{P}$ has been demonstrated to potently stimulate mesoangioblast proliferation in $\mathrm{S}_{1} \mathrm{P}_{2}$-dependent manner (Donati et al., 2007a). Moreover, the bioactive sphingolipid successfully contrasted the apoptosis induced by different apoptogenic stimuli, without engagement of S1PR. It is important to note that pre-treatment of mesoangioblasts with S1P enhanced their survival when injected in the tibialis anterior muscle of $\alpha$-sarcoglycan null dystrophic mice, further supporting a role for the sphingolipid in preventing programmed cell death. Moreover, the SK/S1P axis was found to be involved in the anti-apoptotic action exerted by TGF $\beta$ in these cells (Donati et al., 2009). RNA silencing or overexpression of dominant negative mutant form of SK1 highlighted a key role of SK1 but not SK2 in mediating TGF $\beta$ pro-survival action. The cytokine increased SK activity and up-regulated SK1 expression 
which was down-regulated by the apoptotic challenge. A successive study demonstrated the crucial role of the cross-talk between S1P and TGF $\beta$ in the biology of mesoangioblasts. Data obtained by a cDNA microarray study, validated by real time PCR and immunofluorescence microscopy approaches, highlighted that $\mathrm{S} 1 \mathrm{P}$ exerts a strong differentiating action of mesoangioblasts toward smooth muscle cells. Interestingly it was shown that S1P axis was required by TGF $\beta$ to exert its differentiating activity toward smooth muscle on mesoangioblasts. The study individuated also the transcription factor GATA6 as a novel player in the complex transcriptional regulation of mesoangioblast differentiation to smooth muscle. S1P up-regulated the expression of GATA6 which was responsible for the enhanced expression of smooth muscle contractile proteins. By specific silencing of GATA6 it was demonstrated that the transcription factor was critical also in the pro-differentiating activity of TGF $\beta$ (Donati et al., 2011).

ASC are mesenchymal stem cells able to differentiate into different mesodermal lineages (Chamberlain et al., 2007). Being relatively easy to isolate and able to rapidly proliferate in vitro, these cells are promising in the development of cell therapy tools. S1P administration to ASC up-regulated the expression of smooth muscle protein markers, induced the appearance of calcium currents and of actin cytoskeleton reorganization typical of smooth muscle cells. S1P differentiating action was found to rely on $\mathrm{S}_{1} \mathrm{P}_{2}$ engagement while $\mathrm{S}_{1} \mathrm{P}_{3}$ role was less critical (Nincheri et al., 2009).

\section{BIOLOGICAL ROLE OF S1P SIGNALING AXIS IN MYOBLASTS}

$\mathrm{C} 2 \mathrm{C} 12$ cell line is a subclone of the parental $\mathrm{C} 2$ cells which differentiate into myotubes in appropriate culture condition, after serum deprivation (Yaffe and Saxel, 1977; Blau et al., 1985). This model is therefore widely used as a tool to study the myogenic differentiation process and the involved molecular mechanisms.

C2C12 cells express 4 out of $5 \mathrm{~S} 1 \mathrm{PR}, \mathrm{S}_{1} \mathrm{P}_{1-4}$, being $\mathrm{S}_{1} \mathrm{P}_{1}$ the most expressed receptor (Meacci et al., 2003; Bruni and Donati, 2013; Donati et al., 2013). Earlier reports showed that in C2C12 cells exogenous S1P activates a number of signaling pathways: indeed it induced a rapid stimulation of phospholipase D activity (Meacci et al., 1999) and a transient and rapid membrane association of RhoA (Meacci et al., 2000) in a PKC-dependent manner. Moreover, the bioactive lipid was demonstrated to induce $\mathrm{Ca}^{2+}$ mobilization in a $\mathrm{S}_{2} \mathrm{P}_{2 / 3}$-dependent manner (Meacci et al., 2002). Interestingly, differentiation of $\mathrm{C} 2 \mathrm{C} 12$ myoblasts into myotubes was accompanied by deep changes in expression of S1PR. Indeed, $\mathrm{S}_{1} \mathrm{P}_{2}$ was down-regulated while $\mathrm{S}_{1} \mathrm{P}_{3}$ was up-regulated in differentiated cells (Meacci et al., 2003), suggesting that $\mathrm{S}_{1} \mathrm{P}_{2}$ plays a role in myoblasts but is dispensable in myotubes. The crucial role of $\mathrm{S} \mathrm{P}_{2}$ in myogenic differentiation of $\mathrm{C} 2 \mathrm{C} 12$ myoblasts was demonstrated in a later study, where S1P was shown to exert via this receptor subtype a negative action on serum-induced proliferation and to act as a potent inducer of differentiation (Donati et al., 2005). The role of $\mathrm{S} \mathrm{P}_{2}$ was demonstrated by pharmacological and genetic approaches. The involvement of $\mathrm{S}_{2} \mathrm{P}_{2}$ in myogenic differentiation was further confirmed by a subsequent report where the compound K6PC5, a synthetic derivative of ceramide, previously shown to induce SK1 activation in keratinocytes (Kwon et al., 2007), stimulated myoblast differentiation in a $\mathrm{S}_{1} \mathrm{P}_{2}$-dependent manner (Bernacchioni et al., 2011).

$\mathrm{S} \mathrm{P}_{2}$ was also identified as the responsible for the inhibitory effect on myoblast directional motility and insulin like growth factor-1 (IGF-1)-induced chemotaxis exerted by S1P in C2C12 myoblasts (Becciolini et al., 2006), in line with the anti-migratory action of this receptor demonstrated in other cell systems (Arikawa et al., 2003; Lepley et al., 2005). In this study was also established the involvement of RhoA activation in the negative regulation of cell motility.

During muscle regeneration, following satellite cell activation and migration to the site of lesion, inhibition of myoblast motility and differentiation into myotubes takes place in a highly orchestrated manner. In view of its role as muscle pleiotropic regulatory molecule, S1P exerts a dual role on cell migration, stimulating at first migration of activated satellite cells (Calise et al., 2012) and then inhibiting that of C2C12 myoblasts (Becciolini et al., 2006), subsequently to a timely remodeling of S1PR expression pattern, thus favoring skeletal muscle repair (Table 1).

During in vitro differentiation of $\mathrm{C} 2 \mathrm{C} 12$ myoblasts, a small population of cells, named reserve cells remains undifferentiated, thus resembling quiescent satellite cells (Yoshida et al., 1998). The analysis of the role of S1PR in regulating cell proliferation highlighted that in reserve cells, S1P, via specific coupling to $\mathrm{S}_{1} \mathrm{P}_{1}$, stimulates cell proliferation similarly to what demonstrated in satellite cells but differently from what shown in myoblasts (Rapizzi et al., 2008). In view of the finely regulated expression of S1PR during commitment and differentiation of myogenic precursors which drive different biological outcomes of the bioactive lipid, future studies are required to characterize the specific molecular mechanisms regulating the differential expression of S1PR and their coupling.

Successive studies have elucidated some downstream events implicated in the promyogenic effect of the sphingolipid. Indeed, exogenous addition of S1P to $\mathrm{C} 2 \mathrm{C} 12$ myoblasts up-regulated the expression of the gap junctional protein connexin-43 (Squecco et al., 2006), and the transient receptor potential cation channel, a component of the stretch activated channel (Formigli et al., 2007; Meacci et al., 2010).

The role of S1P metabolism, with special attention to SK, the enzyme responsible for S1P production, in the regulation of $\mathrm{C} 2 \mathrm{C} 12$ cell growth and differentiation has been highlighted. Indeed, the expression of SK1 was found to be enhanced in differentiating myoblasts (Meacci et al., 2008). Additionally, when overexpressed, SK1 was responsible for a significative reduction of

Table 1 | Role of sphingosine 1-phosphate on cell proliferation and migration in myoblasts and activated satellite cells.

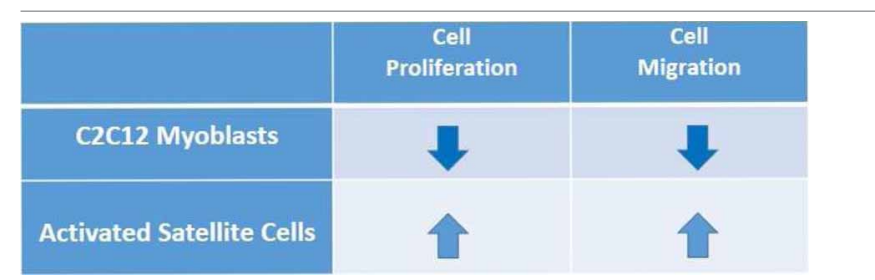


myoblast proliferation rate, while it enhanced the appearance of a differentiated phenotype and the expression of myogenic marker proteins. On the contrary, when SK1 was silenced or a dominant negative mutant form of the enzyme was overexpressed, myoblast proliferation was increased and myogenic differentiation rate was reduced. The role of $\mathrm{S}_{1} \mathrm{P}_{2}$ in myogenic differentiation was also confirmed in this study, since when the receptor was silenced, the pro-myogenic action of SK1 overexpression was abolished. Therefore, although in the literature SK1 has been reported to have a mitogenic role (Maceyka et al., 2012), in myoblasts this enzyme displays an opposite biological effect.

As outlined above, SK activity is under the control of a variety of growth factors, cytokines, neurotransmitters, and hormones (Maceyka et al., 2012), which leads to the existence of functional cross-talks further complicating S1P signaling. Following the demonstration of the role of SK1 in myogenesis, several reports have shown that a number of growth factors and cytokine, known as crucial regulator of skeletal muscle biology, co-opt S1P signaling (Figures 1, 2). The pro-inflammatory cytokine $\mathrm{TNF} \alpha$, which is critically implicated in the remodeling of skeletal muscle (Li and Schwartz, 2001), at low doses has been shown to translocate $\mathrm{SK} 1$ to membrane and, via $\mathrm{S}_{1} \mathrm{P}_{2}$ engagement, to stimulate C2C12 myoblast differentiation (Donati et al., 2007b). Notably, IGF-1, one of the most important physiological regulator of skeletal muscle regeneration (Pedersen and Febbraio, 2012), activates both SK isoforms, SK1 and SK2, and via specific transactivation of $\mathrm{S}_{1} \mathrm{P}_{2}$, exerts its myogenic action (Bernacchioni et al., 2012). Moreover, IGF-1 is also responsible for SK-dependent transactivation of $\mathrm{S}_{1} \mathrm{P}_{1}$ and $\mathrm{S}_{3} \mathrm{P}_{3}$ that in turn reduce the mitogenic effect of the growth factor.

Interestingly, also platelet derived growth factor (PDGF), another growth factor relevant for the biology and the repair of skeletal muscle (Husmann et al., 1996), exerts a negative role on myoblast proliferation via selective SK1 activation and $\mathrm{S}_{1} \mathrm{P}_{1}$ transactivation. Moreover, $\mathrm{S} 1 \mathrm{P}$ inside-out signaling and $\mathrm{S}_{1} \mathrm{P}_{1}$ engagement appear to be necessary for conveying of PDGF-induced chemotactic action. It is important to note that despite the importance of $\mathrm{S}_{1} \mathrm{P}_{1}$ engagement in the biological action of IGF-1 and PDGF in myoblasts, $\mathrm{S}_{1} \mathrm{P}_{1}$ down-regulation or pharmacological inhibition did not affect the biological responses evoked by exogenously added S1P (Donati et al., 2005; Becciolini et al., 2006). This observation suggests that spatial regulation of S1P generation inside the cell is critical for determining the subset of engaged receptors, its final biological outcomes and that $\mathrm{S}_{1} \mathrm{P}_{1}$ is not freely accessible to its ligand from outside the cell. Indeed, structural evidence indicated that ligand binding to $\mathrm{S}_{1} \mathrm{P}_{1}$ occurs by initial delivery of $\mathrm{S} 1 \mathrm{P}$ to the exterior portion of membrane followed by a lateral diffusion into the receptor binding pocket (O'Sullivan and Dev, 2013).

SK/S1P axis is also exploited by TGF $\beta$ to transmit its profibrotic, anti-differentiating action in $\mathrm{C} 2 \mathrm{C} 12$ myoblasts (Cencetti et al., 2010). Unfortunately, during muscle regeneration, the transdifferentiation of myoblasts and muscle resident fibroblasts into myofibroblasts give rise to muscle fibrosis that reduces muscle contractile properties and impairs full muscular recovery. The cytokine TGF $\beta$ plays a crucial role in the promotion of the fibrosis onset and in the inhibition of myogenesis (McLennan and Koishi, 2002); importantly, the inhibition of TGF $\beta$ signaling pathway has been shown to ameliorate the chronic degenerative fibrosis of dystrophic muscles (Cohn et al., 2007). Indeed, TGF $\beta$ induced a Smad-dependent up-regulation of SK1 expression and activation, which, in contrast to what expected on the basis of the previously demonstrated SK1 role in myogenesis (Donati et al., 2005; Meacci et al., 2008), redirected the final S1P biological outcome from being promyogenic to profibrotic since the cytokine induced also a profound remodeling of S1PR expression pattern, at least at mRNA levels. This was responsible for readdressing the pro-myogenic role mediated through $\mathrm{S}_{1} \mathrm{P}_{2}$ to a pro-fibrotic role mediated by $\mathrm{S}_{3} \mathrm{P}_{3}$, which following TGF $\beta$ administration, became the most expressed receptor. These data support the concept that interfering with $\mathrm{S}_{1} \mathrm{P}_{3}$ signaling might favor therapeutic intervention to reduce skeletal muscle fibrosis.

Very recently a new signaling pathway related to TGF $\beta$ induced apoptosis has been identified in $\mathrm{C} 2 \mathrm{C} 12$ myoblasts which relies on Rho kinase- 2 stimulation, subsequent to SMADdependent TGF $\beta$-induced $\mathrm{S}_{4} \mathrm{P}_{4}$ up-regulation and transactivation via SK2 (Cencetti et al., 2013). This finding supports the notion that $\mathrm{S} \mathrm{P}_{4}$ is up-regulated by TGF $\beta$ and is relevant for the apoptotic action of the cytokine in skeletal muscle.

\section{BIOLOGICAL ROLE OF S1P IN SKELETAL MUSCLE}

Skeletal muscle has the ability to adapt to different physiological and pathological conditions since it displays a high degree of

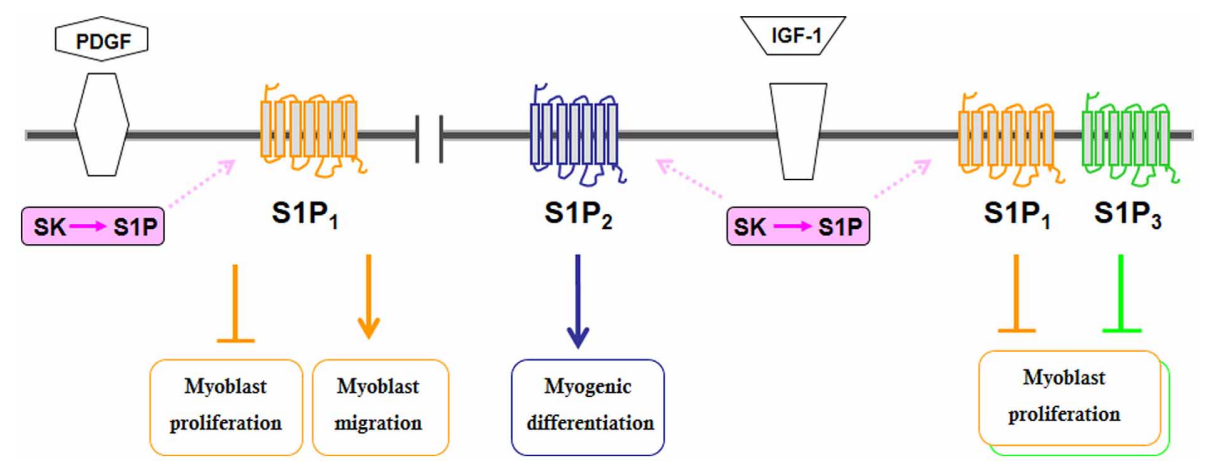

FIGURE 1 | Schematic diagram of the biological actions evoked by S1PR transactivation by some growth factors in C2C12 myoblasts. 


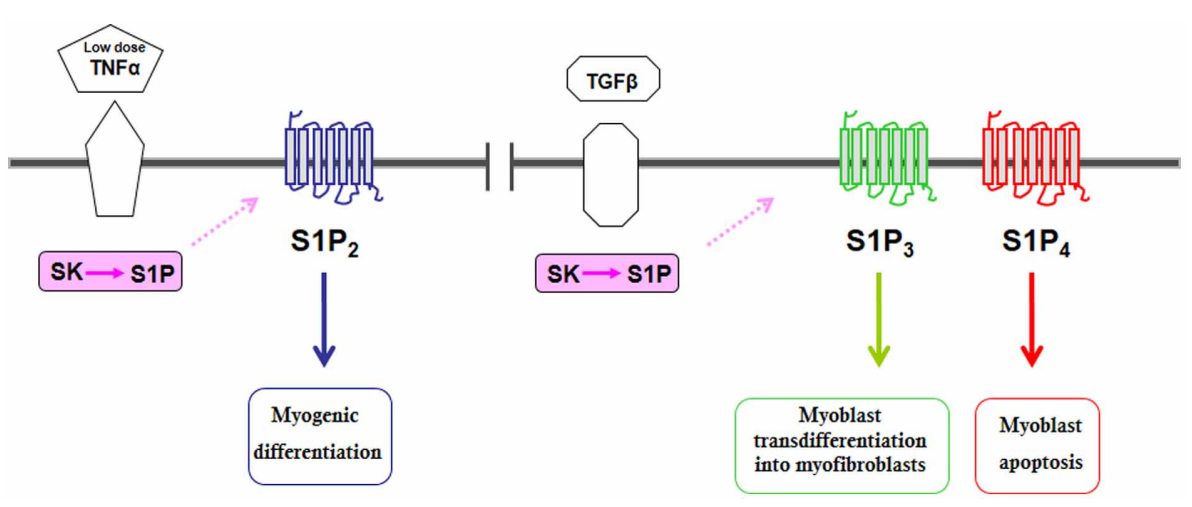

FIGURE 2 | Schematic diagram of the biological actions evoked by S1PR transactivation by some cytokines in C2C12 myoblasts.

plasticity. The size of skeletal muscle fibers results from a balance between protein synthesis and degradation, and varies as a consequence of physiological and pathological circumstances. The increase of individual muscle fibers, i.e., hypertrophy, occurs when protein synthesis exceeds protein degradation in response to hormonal stimulation or mechanical overload. A reduction in skeletal muscle mass and fiber size, i.e., atrophy, occurs in response to catabolic hormonal stimulation, denervation, aging, cancer, bed rest, and starvation (Schiaffino et al., 2013). S1P has been reported to be involved in the regulation of some physiological properties of skeletal muscle such as muscle contractility, fatigue, and adaptation.

Indeed, S1P has been shown to affect the excitationcontraction coupling in fibers isolated from murine extensor digitorum longus (EDL). The bioactive lipid modulated the voltage threshold and the inward calcium current through the dihydropyridine receptor in a $\mathrm{S}_{1} \mathrm{P}_{3}$-dependent manner although the experiments were carried out in the presence of the unspecific receptor antagonist suramin (Bencini et al., 2003).

Zanin et al. (2008) has demonstrated a trophic role for S1P in a rat model of denervation atrophy. S1P, delivered to the muscle through a mini osmotic pump, significantly reduced the negative effects of denervation on muscle mass and cross sectional area (CSA) after 7 and 14 days of regeneration. Moreover, despite its established anti-proliferative and pro-apoptotic role (Bruni and Donati, 2008), also sphingosine exerted a trophic effect, likely due to its conversion to S1P catalyzed by SK, as suggested by the abolishment of the positive action of the sphingolipid in the presence of DMS. Moreover, by real time $\mathrm{PCR}, \mathrm{S}_{1} \mathrm{P}_{1}$, and $\mathrm{S}_{1} \mathrm{P}_{3}$ were found to be selectively expressed, and subjected to down-regulation upon denervation.

The decline in the ability of skeletal muscle to generate force after a strenuous exercise is named muscle fatigue. The process is reversible and depends on multiple factors such as the intensity and the duration of the contraction and the type of fibers of the muscles. Exogenous S1P has been found able of reducing muscle fatigue of EDL muscles (Danieli-Betto et al., 2005). Interestingly, administration of sphingosine significantly diminished the tension decline. Since sphingosine effect was reduced in the presence of the unselective SK inhibitor DMS, it was deduced that the mechanism of action implicates S1P production through SK activation. Indeed the effect of sphingosine, but not that of S1P, was abolished in the absence of $\mathrm{Ca}^{2+}$, suggesting a $\mathrm{Ca}^{2+}$-dependent mechanism of activation of SK.

The role of S1P signaling in skeletal muscle regeneration has been firstly demonstrated in mouse and rat models after myotoxic injury induced by bupivacaine (Danieli-Betto et al., 2010). The administration of S1P after muscle damage induced a significant increase of CSA while the neutralization of circulating S1P by administration of an anti-S1P antibody abolished fiber growth. Western blotting analysis of S1PR expression in muscle lysates during rat soleus regeneration showed dynamic changes of S1PR at protein level suggesting their putative role during regeneration. The S1P-induced increase of regenerating fiber growth was inhibited by a selective $\mathrm{S}_{1} \mathrm{P}_{1}$ agonist and augmented by a selective $\mathrm{S}_{1 / 3} \mathrm{P}_{1 / 3}$ antagonist, supporting a negative role of $\mathrm{S}_{1} \mathrm{P}_{1}$ and a positive role of $\mathrm{S} \mathrm{P}_{3}$ in the early phases of regeneration. In contrast, a very recent study demonstrated that in $\mathrm{S}_{1} \mathrm{P}_{3}$ null mice acute muscle regeneration was enhanced and that genetic ablation of $\mathrm{S}_{3} \mathrm{P}_{3}$ in mdx mice produced a less severe dystrophic phenotype (Fortier et al., 2013). Further studies are therefore required to clarify the exact role of $\mathrm{S}_{1} \mathrm{P}_{3}$ in skeletal muscle regeneration.

Herr et al. (2003) have demonstrated that mutation in the gene that encodes for the homolog of SPL generates Sply mutants in fruit fly that do not catalyze S1P degradation and accumulate S1P. In these mutants the thoracic flight muscles degenerate due to the absence of fibers in the dorsal longitudinal muscles. These findings highlight the importance of sphingolipid metabolism in muscle homeostasis, crucial for adult muscle development and integrity.

Presently, beside mammalian models to study muscular dystrophy including mouse, dog and cat, genetically tractable models have been established in Danio rerio and Drosophila melanogaster (Shcherbata et al., 2007). Very recently, a paper published by Pantoja et al. (2013), demonstrated that suppression of wunen, an homolog of lipid phosphate phosphatase 3, suppresses dystrophic muscle phenotype measured by evaluation of correct localization of the titin-homolog, projectin, in sarcomeres and functional movements. The authors demonstrated that wunen suppression acts through the elevation of S1P levels, since analogous findings were obtained altering S1P levels genetically via down-regulation of SPL or up-regulation of serine palmitoyl-CoA transferase, or 
pharmacologically by oral administration of SPL inhibitors. The same authors have very recently demonstrated that an increase of S1P levels via administration of an SPL inhibitor positively affected acute muscle regeneration of dystrophic mdx mice. The beneficial effects of S1P on increased muscle fiber size, force, diminished fibrosis, and fat accumulation were linked to the ability of S1P of increasing the number of myogenic cells (Ieronimakis et al., 2013).

The role of $\mathrm{S} \mathrm{P}_{2}$ in vivo in the early phases of regeneration has been demonstrated recently by Germinario et al. (2012) after injection of notexin in two mouse model of $\mathrm{S} \mathrm{P}_{2}$ deficiency: the $\mathrm{S}_{1} \mathrm{P}_{2}$ null mice and wild-type mice systemically administered with the $\mathrm{S}_{1} \mathrm{P}_{2}$ antagonist JTE-013. Indeed, the absence of $\mathrm{S}_{1} \mathrm{P}_{2}$ or its blockade delayed the regeneration of skeletal muscle measured as soleus CSA. Interestingly, the systemic administration of an antiS1P antibody, which induced a reduction of soleus fiber growth in wild-type mice was ineffective in the absence of $\mathrm{S}_{2} \mathrm{P}_{2}$.

Microarray study revealed that during mouse skeletal muscle regeneration following notexin injury, while sphk1 gene is upregulated at early time points, sgpll gene is induced several days post injury (Loh et al., 2012). SPL is expressed at very low level in skeletal muscle at rest, while is up-regulated in response to ischemia (Kumar and Saba, 2009) and radiation (Bandhuvula et al., 2011). The specific requirement for SK1 to support muscle regeneration and satellite cell recruitment has been demonstrated in SK1 null mice. Interestingly the plasma of dystrophic mdx mice display reduced S1P levels, comparable to that of SK1 null mice, probably due to a significant up-regulation of sgpll rather than downregulation of $s p h K 1$ or $s p h K 2$ genes. Tetrahydroxybutylimidazole, unspecific inhibitor of SPL, improved the number of regenerating fibers in dystrophic muscles and satellite cell activation. The combination of pharmacological inhibitors, S1PR antagonists and plasmid constructs in vitro showed that $\mathrm{S} 1 \mathrm{P}$ recruits satellite cells through activation on $\mathrm{S}_{\mathrm{PR}} / \mathrm{Rho}$ GTPase/STAT3 signaling axis (Loh et al., 2012).

\section{BIOLOGICAL ROLE OF S1P IN INSULIN RESPONSIVENESS OF SKELETAL MUSCLE}

Skeletal muscle plays a crucial role in the regulation of whole body metabolism. In response to insulin, in fed condition, skeletal muscle is responsible for glucose removal from the bloodstream thus contributing to the majority of glucose disposal for the buildingup of glycogen. Since skeletal muscle utilizes the majority of body glucose, reduced insulin responsiveness in skeletal muscle leads to the development of metabolic syndrome (McGarry, 2002). SK1/S1P axis has recently been implicated in the regulation of glucose metabolism. In $\mathrm{C} 2 \mathrm{C} 12$ myoblasts pharmacological inhibition of SK1 reduced insulin-stimulated glucose uptake while its overexpression mimicked in vivo insulin action. Moreover, overexpression of SK1 gene reduced blood glucose level in diabetic mice (Ma et al., 2007). In keeping with the role of S1P as insulinmimetic cue, a study has reported that in $\mathrm{C} 2 \mathrm{C} 12$ myoblasts $\mathrm{S} 1 \mathrm{P}$, through engagement of $\mathrm{S}_{1} \mathrm{P}_{2}$, produces a transient burst of reactive oxygen species which is sensed by protein tyrosine phosphatase-1B, the main negative regulator of insulin receptor phosphorylation, which undergoes inhibition. This blockade provokes a ligand-independent trans-phosphorylation of insulin receptor and a strong increase in glucose uptake (Rapizzi et al., 2009). This study appears to provide the possible mechanistic explanation of the insulin-mimetic action of SK1 overexpression, highlighting a feedback responsible for the sustained activation of insulin receptor. Since in this study possible implications of S1Pdirected insulin signaling in diabetes were not established, future studies are required aimed at clarifying whether impaired S1P signaling contributes to the development of insulin resistance and whether improvement of $\mathrm{S} 1 \mathrm{P} / \mathrm{S}_{1} \mathrm{P}_{2}$ signaling would be beneficial for glucose disposal by skeletal muscle.

In addition to the role of elevated triacylglycerol levels in skeletal muscle for the development of insulin sensitivity (McGarry, 2002), a number of reports support the role of ceramide for diminished insulin responsiveness. Taking into account that SK plays a crucial role in the regulation of the relative levels of ceramide/sphingosine and S1P, it will be of crucial interest in the future to understand whether the biological effects observed as consequence of SK overexpression are due to specific S1Pinduced signaling or rather to diminution of ceramide cellular levels.

In this line, transgenic mice overexpressing SK1 display improved insulin sensitivity compared to wild-type animal after a 6 week high fat diet, due to increased SK activity in skeletal muscle and decreased intracellular ceramide content (Bruce et al., 2012). The same authors have demonstrated that daily treatment with FTY720, that acts as functional antagonist of S1PR and has been reported to inhibit the activity of ceramide synthase in vitro (Berdyshev et al., 2009; Lahiri et al., 2009), for 6 weeks after an high fat diet improved mice glucose tolerance, insulin uptake and Akt phosphorylation through ceramide, diacylglycerol, and triacylglycerol reduction in muscle (Bruce et al., 2013). Interestingly, the expression levels of the enzymes involved in sphingolipid metabolism were not altered.

It has been demonstrated that treatment with palmitate in $\mathrm{C} 2 \mathrm{C} 12$ myotubes increased $\mathrm{S} 1 \mathrm{P}$ as consequence of increased expression and activity of SK1 (Hu et al., 2009). Very recently, in the context of free fatty acid oversupply it has been shown that SK1 is regulated at transcriptional level by the transcription factor PPAR $\alpha$ in C2C12 cells (Ross et al., 2013). Moreover, specifically in skeletal muscle palmitate treatment induced the expression of IL-6 and its downstream signaling in a SK1- and $\mathrm{S}_{1} \mathrm{P}_{3}$-dependent manner. IL-6 expression, which is up-regulated in diet-induced obese mice, was attenuated in SK1 null mice. IL- 6 produced by skeletal muscle is the prototype of an emerging class of cytokines named myokines which mediate the cross-talk between muscle and other tissues. The role of IL- 6 and its signaling in skeletal muscle of obese mice remain unaddressed in this study. Since several studies have reported that muscular IL- 6 has a role in metabolism rather than in inflammation, working as an energy sensor and as a lipolytic factor (Pedersen and Febbraio, 2012), the role of SK in the regulation of IL-6 expression and release by skeletal muscle should also be therefore further investigated in other experimental settings.

\section{CONCLUSION}

Overall, the here reported experimental findings highlight the fundamental role of S1P signaling axis in skeletal muscle biology. 
Future studies will confidently dissect in detail the molecular mechanisms that regulate S1P metabolism and S1PR expression in the various aspects of skeletal muscle biology and hopefully they will bring to characterize the therapeutic potential of S1P signaling pathway in skeletal muscle diseases.

\section{ACKNOWLEDGMENTS}

This work was supported in part by funds from the University of Florence, Fondazione Cassa di Risparmio di Lucca e PRIN 2009 to Paola Bruni.

\section{REFERENCES}

Alvarez, S. E., Harikumar, K. B., Hait, N. C., Allegood, J., Strub, G. M., Kim, E. Y., et al. (2010). Sphingosine-1-phosphate is a missing cofactor for the E3 ubiquitin ligase TRAF2. Nature 465, 1084-1088. doi: 10.1038/nature09128

Arikawa, K., Takuwa, N., Yamaguchi, H., Sugimoto, N., Kitayama, J., Nagawa, H., et al. (2003). Ligand-dependent inhibition of B16 melanoma cell migration and invasion via endogenous S1P2 G protein-coupled receptor. Requirement of inhibition of cellular RAC activity. J. Biol. Chem. 278, 32841-32851. doi: 10.1074/jbc.M305024200

Bandhuvula, P., Honbo, N., Wang, G. Y., Jin, Z. Q., Fyrst, H., Zhang, M., et al. (2011). S1P lyase: a novel therapeutic target for ischemia-reperfusion injury of the heart. Am. J. Physiol. Heart Circ. Physiol. 300, H1753-H1761. doi: 10.1152/ajpheart.00946.2010

Becciolini, L., Meacci, E., Donati, C., Cencetti, F., Rapizzi, E., and Bruni, P. (2006). Sphingosine 1-phosphate inhibits cell migration in C2C12 myoblasts. Biochim. Biophys. Acta 1761, 43-51. doi: 10.1016/j.bbalip.2006.01.006

Bencini, C., Squecco, R., Piperio, C., Formigli, L., Meacci, E., Nosi, D., et al. (2003). Effects of sphingosine 1-phosphate on excitation-contraction coupling in mammalian skeletal muscle. J. Muscle Res. Cell. Motil. 24, 539-554. doi: 10.1023/B:JURE.0000009898.02325.58

Berdyshev, E. V., Gorshkova, I., Skobeleva, A., Bittman, R., Lu, X., Dudek, S. M., et al. (2009). FTY720 inhibits ceramide synthases and up-regulates dihydrosphingosine 1-phosphate formation in human lung endothelial cells. J. Biol. Chem. 284, 5467-5477. doi: 10.1074/jbc.M805186200

Bernacchioni, C., Cencetti, F., Blescia, S., Donati, C., and Bruni, P. (2012). Sphingosine kinase/sphingosine 1-phosphate axis: a new player for insulinlike growth factor-1-induced myoblast differentiation. Skelet. Muscle 2, 15. doi: 10.1186/2044-5040-2-15

Bernacchioni, C., Cencetti, F., Kwon, M. J., Gwak, H. S., Jeong, S. K., Bruni, P., et al. (2011). The sphingosine kinase activator K6PC-5 stimulates C2C12 myoblast differentiation. Int. J. Immunopathol. Pharmacol. 24, 55-62.

Blau, H. M., Pavlath, G. K., Hardeman, E. C., Chiu, C. P., Silberstein, L., Webster, S. G., et al. (1985). Plasticity of the differentiated state. Science 230, 758-766. doi: $10.1126 /$ science. 2414846

Bruce, C. R., Risis, S., Babb, J. R., Yang, C., Kowalski, G. M., Selathurai, A., et al. (2012). Overexpression of sphingosine kinase 1 prevents ceramide accumulation and ameliorates muscle insulin resistance in high-fat diet-fed mice. Diabetes 61, 3148-3155. doi: 10.2337/db12-0029

Bruce, C. R., Risis, S., Babb, J. R., Yang, C., Lee-Young, R. S., Henstridge, D. C., et al. (2013). The sphingosine-1-phosphate analog FTY720 reduces muscle ceramide content and improves glucose tolerance in high fat-fed male mice. Endocrinology 154, 65-76. doi: 10.1210/en.2012-1847

Bruni, P., and Donati, C. (2008). Pleiotropic effects of sphingolipids in skeletal muscle. Cell. Mol. Life Sci. 65, 3725-3736. doi: 10.1007/s00018-008-8236-6

Bruni, P., and Donati, C. (2013). Role of sphingosine 1-phosphate in skeletal muscle cell biology. Handb. Exp. Pharmacol. 216, 457-467. doi: 10.1007/978-3-70911511-4_23

Calise, S., Blescia, S., Cencetti, F., Bernacchioni, C., Donati, C., and Bruni, P. (2012). Sphingosine 1-phosphate stimulates proliferation and migration of satellite cells: role of S1P receptors. Biochim. Biophys. Acta 1823, 439-450. doi: 10.1016/j.bbamcr.2011.11.016

Carlson, M. E., and Conboy, I. M. (2007). Loss of stem cell regenerative capacity within aged niches. Aging Cell 6, 371-382. doi: 10.1111/j.14749726.2007.00286.x

Cencetti, F., Bernacchioni, C., Nincheri, P., Donati, C., and Bruni, P. (2010). Transforming growth factor-betal induces transdifferentiation of myoblasts into myofibroblasts via up-regulation of sphingosine kinase-1/S1P3 axis. Mol. Biol. Cell 21, 1111-1124. doi: 10.1091/mbc.E09-09-0812

Cencetti, F., Bernacchioni, C., Tonelli, F., Roberts, E., Donati, C., and Bruni, P. (2013). TGF $\beta 1$ evokes myoblast apoptotic response via a novel signaling pathway involving S1P4 transactivation upstream of Rho-kinase-2 activation. FASEB J. 27, 4532-4546. doi: 10.1096/fj.13-228528

Chakkalakal, J. V., Jones, K. M., Basson, M. A., and Brack, A. S. (2012). The aged niche disrupts muscle stem cell quiescence. Nature 490, 355-360. doi: $10.1038 /$ nature 11438

Chamberlain, G., Fox, J., Ashton, B., and Middleton, J. (2007). Concise review: mesenchymal stem cells: their phenotype, differentiation capacity, immunological features, and potential for homing. Stem Cells 25, 2739-2749. doi: 10.1634/stemcells.2007-0197

Chargé, S. B., and Rudnicki, M. A. (2004). Cellular and molecular regulation of muscle regeneration. Physiol. Rev. 84, 209-238. doi: 10.1152/physrev.00019.2003

Cohn, R. D., van Erp, C., Habashi, J. P., Soleimani, A. A., Klein, E. C., Lisi, M. T., et al. (2007). Angiotensin II type 1 receptor blockade attenuates TGF-betainduced failure of muscle regeneration in multiple myopathic states. Nat. Med. 13, 204-210. doi: 10.1038/nm1536

Collins, C. A., Olsen, I., Zammit, P. S., Heslop, L., Petrie, A., Partridge, T. A., et al. (2005). Stem cell function, self-renewal, and behavioral heterogeneity of cells from the adult muscle satellite cell niche. Cell 122, 289-301. doi: 10.1016/j.cell.2005.05.010

Danieli-Betto, D., Germinario, E., Esposito, A., Megighian, A., Midrio, M., Ravara, B., et al. (2005). Sphingosine 1-phosphate protects mouse extensor digitorum longus skeletal muscle during fatigue. Am. J. Physiol. Cell Physiol. 288, C1367-C1373. doi: 10.1152/ajpcell.00246.2004

Danieli-Betto, D., Peron, S., Germinario, E., Zanin, M., Sorci, G., Franzoso, S., et al. (2010). Sphingosine 1-phosphate signaling is involved in skeletal muscle regeneration. Am. J. Physiol. Cell Physiol. 298, C550-C558. doi: 10.1152/ajpcell.00072.2009

Dellavalle, A., Maroli, G., Covarello, D., Azzoni, E., Innocenzi, A., Perani, L., et al. (2011). Pericytes resident in postnatal skeletal muscle differentiate into muscle fibres and generate satellite cells. Nat. Commun. 2, 499. doi: 10.1038/ncomms 1508

Dhawan, J., and Rando, T. A. (2005). Stem cells in postnatal myogenesis: molecular mechanisms of satellite cell quiescence, activation and replenishment. Trends Cell Biol. 15, 666-673. doi: 10.1016/j.tcb.2005.10.007

Divangahi, M., Balghi, H., Danialou, G., Comtois, A. S., Demoule, A., Ernest, S., et al. (2009). Lack of CFTR in skeletal muscle predisposes to muscle wasting and diaphragm muscle pump failure in cystic fibrosis mice. PLoS Genet. 5:e1000586. doi: 10.1371/journal.pgen.1000586

Donati, C., Cencetti, F., and Bruni, P. (2013). New insights into the role of sphingosine 1-phosphate and lysophosphatidic acid in the regulation of skeletal muscle cell biology. Biochim. Biophys. Acta 1831, 176-184. doi: 10.1016/j.bbalip.2012.06.013

Donati, C., Cencetti, F., De Palma, C., Rapizzi, E., Brunelli, S., Cossu, G., et al. (2009). TGFbeta protects mesoangioblasts from apoptosis via sphingosine kinase-1 regulation. Cell. Signal. 21, 228-236. doi: 10.1016/j.cellsig.2008.10.007

Donati, C., Cencetti, F., Nincheri, P., Bernacchioni, C., Brunelli, S., Clementi, E., et al. (2007a). Sphingosine 1-phosphate mediates proliferation and survival of mesoangioblasts. Stem Cells 25, 1713-1719. doi: 10.1634/stemcells. 2006-0725

Donati, C., Nincheri, P., Cencetti, F., Rapizzi, E., Farnararo, M., and Bruni, P. (2007b). Tumor necrosis factor-alpha exerts pro-myogenic action in C2C12 myoblasts via sphingosine kinase/S1P2 signaling. FEBS Lett. 581, 4384-4388. doi: 10.1016/j.febslet.2007.08.007

Donati, C., Marseglia, G., Magi, A., Serrati, S., Cencetti, F., Bernacchioni, C., et al. (2011). Sphingosine 1-phosphate induces differentiation of mesoangioblasts towards smooth muscle. A role for GATA6. PLoS ONE 6:e20389. doi: 10.1371/journal.pone.0020389

Donati, C., Meacci, E., Nuti, F., Becciolini, L., Farnararo, M., and Bruni, P. (2005). Sphingosine 1-phosphate regulates myogenic differentiation: a major role for S1P2 receptor. FASEB J. 19, 449-451. doi: 10.1096/fj.04-1780fje

Formigli, L., Meacci, E., Sassoli, C., Squecco, R., Nosi, D., Chellini, F., et al. (2007). Cytoskeleton/stretch-activated ion channel interaction regulates myogenic differentiation of skeletal myoblasts. J. Cell. Physiol. 211, 296-306. doi: $10.1002 /$ jcp. 20936 
Fortier, M., Figeac, N., White, R. B., Knopp, P., and Zammit, P. S. (2013). Sphingosine-1-phosphate receptor 3 influences cell cycle progression in muscle satellite cells. Dev. Biol. 382, 504-516. doi: 10.1016/j.ydbio.2013.07.006

García-Prat, L., Sousa-Victor, P., and Muñoz-Cánoves, P. (2013). Functional dysregulation of stem cells during aging: a focus on skeletal muscle stem cells. FEBS J. 280, 4051-4062. doi: 10.1111/febs.12221

Germinario, E., Peron, S., Toniolo, L., Betto, R., Cencetti, F., Donati, C., et al. (2012). S1P2 receptor promotes mouse skeletal muscle regeneration. J. Appl. Physiol. 113, 707-713. doi: 10.1152/japplphysiol.00300.2012

Hait, N. C., Allegood, J., Maceyka, M., Strub, G. M., Harikumar, K. B., Singh, S. K., et al. (2009). Regulation of histone acetylation in the nucleus by sphingosine-1phosphate. Science 325, 1254-1257. doi: 10.1126/science.1176709

Hait, N. C., Bellamy, A., Milstien, S., Kordula, T., and Spiegel, S. (2007). Sphingosine kinase type 2 activation by ERK-mediated phosphorylation. J. Biol. Chem. 282, 12058-12065. doi: 10.1074/jbc.M609559200

Hannun, Y. A., and Obeid, L. M. (2008). Principles of bioactive lipid signalling: lessons from sphingolipids. Nat. Rev. Mol. Cell Biol. 9, 139-150. doi: $10.1038 / \mathrm{nrm} 2329$

Herr, D. R., Fyrst, H., Phan, V., Heinecke, K., Georges, R., Harris, G. L., et al. (2003). Sply regulation of sphingolipid signaling molecules is essential for Drosophila development. Development 130, 2443-2453. doi: 10.1242/dev.00456

Hu, W., Bielawski, J., Samad, F., Merrill, A. H. Jr., and Cowart, L. A. (2009) Palmitate increases sphingosine-1-phosphate in C2C12 myotubes via upregulation of sphingosine kinase message and activity. J. Lipid Res. 50, 1852-1862. doi: 10.1194/jlr.M800635-JLR200

Husmann, I., Soulet, L., Gautron, J., Martelly, I., and Barritault, D. (1996). Growth factors in skeletal muscle regeneration. Cytokine Growth Factor Rev. 7, 249-258. doi: 10.1016/S1359-6101(96)00029-9

Ieronimakis, N., Pantoja, M., Hays, A. L., Dosey, T. L., Qi, J., Fischer, K. A., et al. (2013). Increased sphingosine-1-phosphate improves muscle regeneration in acutely injured mdx mice. Skelet. Muscle 3, 20. doi: 10.1186/2044-5040-3-20

Judson, R. N., Zhang, R. H., and Rossi, F. M. (2013). Tissue-resident mesenchymal stem/progenitor cells in skeletal muscle: collaborators or saboteurs. FEBS J. 280, 4100-4108. doi: 10.1111/febs. 12370

Kawahara, A., Nishi, T., Hisano, Y., Fukui, H., Yamaguchi, A., and Mochizuki, N. (2009). The sphingolipid transporter spns2 functions in migration of zebrafish myocardial precursors. Science 323, 524-527. doi: 10.1126/science.1167449

Kono, M., Belyantseva, I. A., Skoura, A., Frolenkov, G. I., Starost, M. F., Dreier, J. L., et al. (2007). Deafness and stria vascularis defects in S1P2 receptor-null mice. J. Biol. Chem. 282, 10690-10696. doi: 10.1074/jbc.M700370200

Kumar, A., and Saba, J. D. (2009). Lyase to live by: sphingosine phosphate lyase as a therapeutic target. Expert Opin. Ther. Targets 13, 1013-1025. doi: $10.1517 / 14728220903039722$

Kwon, Y. B., Kim, C. D., Youm, J. K., Gwak, H. S., Park, B. D., Lee, S. H., et al. (2007). Novel synthetic ceramide derivatives increase intracellular calcium levels and promote epidermal keratinocyte differentiation. J. Lipid Res. 48, 1936-1943. doi: 10.1194/jlr.M700185-JLR200

LaBarge, M. A., and Blau, H. M. (2002). Biological progression from adult bone marrow to mononucleate muscle stem cell to multinucleate muscle fiber in response to injury. Cell 111, 589-601. doi: 10.1016/S0092-8674(02) 01078-4

Lahiri, S., Park, H., Laviad, E. L., Lu, X., Bittman, R., and Futerman, A. H. (2009). Ceramide synthesis is modulated by the sphingosine analog FTY720 via a mixture of uncompetitive and noncompetitive inhibition in an AcylCoA chain length-dependent manner. J. Biol. Chem. 284, 16090-16098. doi: 10.1074/jbc.M807438200

Lebman, D. A., and Spiegel, S. (2008). Cross-talk at the crossroads of sphingosine1-phosphate, growth factors, and cytokine signaling. J. Lipid Res. 49, 1388-1394. doi: 10.1194/jlr.R800008-JLR200

Lepley, D., Paik, J. H., Hla, T., and Ferrer, F. (2005). The G protein-coupled receptor $\mathrm{S} 1 \mathrm{P} 2$ regulates Rho/Rho kinase pathway to inhibit tumor cell migration. Cancer Res. 65, 3788-3795. doi: 10.1158/0008-5472.CAN-04-2311

Le Stunff, H., Giussani, P., Maceyka, M., Lepine, S., Milstien, S., and Spiegel, S. (2007). Recycling of sphingosine is regulated by the concerted actions of sphingosine-1-phosphate phosphohydrolase 1 and sphingosine kinase 2. J. Biol. Chem. 282, 34372-34380. doi: 10.1074/jbc.M703329200

Li, Y. P., and Schwartz, R. J. (2001). TNF-alpha regulates early differentiation of $\mathrm{C} 2 \mathrm{C} 12$ myoblasts in an autocrine fashion. FASEB J. 15, 1413-1415. doi: 10.1096/fj.00-0632fje
Liu, Y., Wada, R., Yamashita, T., Mi, Y., Deng, C. X., Hobson, J. P., et al. (2000). Edg-1, the G protein-coupled receptor for sphingosine-1-phosphate, is essential for vascular maturation. J. Clin. Invest. 106, 951-961. doi: 10.1172/JCI10905

Loh, K. C., Leong, W. I., Carlson, M. E., Oskouian, B., Kumar, A., Fyrst, H., et al. (2012). Sphingosine-1-phosphate enhances satellite cell activation in dystrophic muscles through a S1PR2/STAT3 signaling pathway. PLoS ONE 7:e37218. doi: 10.1371/journal.pone.0037218

Ma, M. M., Chen, J. L., Wang, G. G., Wang, H., Lu, Y., Li, J. F., et al. (2007). Sphingosine kinase 1 participates in insulin signalling and regulates glucose metabolism and homeostasis in KK/Ay diabetic mice. Diabetologia 50, 891-900. doi: 10.1007/s00125-006-0589-5

Maceyka, M., Harikumar, K. B., Milstien, S., and Spiegel, S. (2012). Sphingosine1-phosphate signaling and its role in disease. Trends Cell Biol. 22, 50-60. doi: 10.1016/j.tcb.2011.09.003

McGarry, J. D. (2002). Banting lecture 2001: dysregulation of fatty acid metabolism in the etiology of type 2 diabetes. Diabetes 51, 7-18. doi: 10.2337/diabetes.51.1.7 McLennan, I. S., and Koishi, K. (2002). The transforming growth factor-betas: multifaceted regulators of the development and maintenance of skeletal muscles, motoneurons and Schwann cells. Int. J. Dev. Biol. 46, 559-567.

Meacci, E., Bini, F., Sassoli, C., Martinesi, M., Squecco, R., Chellini, F., et al. (2010). Functional interaction between TRPC1 channel and connexin-43 protein: a novel pathway underlying S1P action on skeletal myogenesis. Cell. Mol. Life Sci. 67, 4269-4285. doi: 10.1007/s00018-010-0442-3

Meacci, E., Cencetti, F., Donati, C., Nuti, F., Farnararo, M., Kohno, T., et al. (2003). Down-regulation of EDG5/S1P2 during myogenic differentiation results in the specific uncoupling of sphingosine 1-phosphate signalling to phospholipase D. Biochim. Biophys. Acta 1633, 133-142. doi: 10.1016/S1388-1981(03)00106-9

Meacci, E., Cencetti, F., Formigli, L., Squecco, R., Donati, C., Tiribilli, B., et al. (2002). Sphingosine 1-phosphate evokes calcium signals in $\mathrm{C} 2 \mathrm{C} 12$ myoblasts via Edg3 and Edg5 receptors. Biochem. J. 362 (Pt 2), 349-357. doi: 10.1042/02646021:3620349

Meacci, E., Donati, C., Cencetti, F., Romiti, E., and Bruni, P. (2000). Permissive role of protein kinase $\mathrm{C}$ alpha but not protein kinase $\mathrm{C}$ delta in sphingosine 1-phosphate-induced Rho A activation in C2C12 myoblasts. FEBS Lett. 482, 97-101. doi: 10.1016/S0014-5793(00)02039-1

Meacci, E., Nuti, F., Donati, C., Cencetti, F., Farnararo, M., and Bruni, P. (2008). Sphingosine kinase activity is required for myogenic differentiation of $\mathrm{C} 2 \mathrm{C} 12$ myoblasts. J. Cell. Physiol. 214, 210-220. doi: 10.1002/jcp.21187

Meacci, E., Vasta, V., Donati, C., Farnararo, M., and Bruni, P. (1999). Receptormediated activation of phospholipase $\mathrm{D}$ by sphingosine 1-phosphate in skeletal muscle C2C12 cells. A role for protein kinase C. FEBS Lett. 457, 184-188. doi: 10.1016/S0014-5793(99)01033-9

Meissner, A., Yang, J., Kroetsch, J. T., Sauvé, M., Dax, H., Momen, A., et al. (2012) Tumor necrosis factor- $\alpha$-mediated downregulation of the cystic fibrosis transmembrane conductance regulator drives pathological sphingosine-1-phosphate signaling in a mouse model of heart failure. Circulation 125, 2739-2750. doi: 10.1161/CIRCULATIONAHA.111.047316

Minasi, M. G., Riminucci, M., De Angelis, L., Borello, U., Berarducci, B., Innocenzi, A., et al. (2002). The meso-angioblast: a multipotent, self-renewing cell that originates from the dorsal aorta and differentiates into most mesodermal tissues. Development 129, 2773-2783.

Mitchell, K. J., Pannerec, A., Cadot, B., Parlakian, A., Besson, V., Gomes, E. R., et al. (2010). Identification and characterization of a non-satellite cell muscle resident progenitor during postnatal development. Nat. Cell Biol. 12, 257-266. doi: $10.1038 /$ ncb2025

Mitra, P., Oskeritzian, C. A., Payne, S. G., Beaven, M. A., Milstien, S., and Spiegel, S. (2006). Role of ABCC1 in export of sphingosine-1-phosphate from mast cells. Proc. Natl. Acad. Sci. U.S.A. 103, 16394-16399. doi: 10.1073/pnas.0603734103

Nagata, Y., Partridge, T. A., Matsuda, R., and Zammit, P. S. (2006). Entry of muscle satellite cells into the cell cycle requires sphingolipid signaling. J. Cell Biol. 174, 245-253. doi: 10.1083/jcb.200605028

Nincheri, P., Luciani, P., Squecco, R., Donati, C., Bernacchioni, C., Borgognoni, L., et al. (2009). Sphingosine 1-phosphate induces differentiation of adipose tissue-derived mesenchymal stem cells towards smooth muscle cells. Cell. Mol. Life Sci. 66, 1741-1754. doi: 10.1007/s00018009-9181-8

Olivera, A., and Spiegel, S. (1993). Sphingosine 1-phosphate as second messenger in cell proliferation induced by PDGF and FCS mitogens. Nature 365, 557-560. doi: $10.1038 / 365557 \mathrm{a} 0$ 
O'Sullivan, C., and Dev, K. K. (2013). The structure and function of the S1P1 receptor. Trends Pharmacol. Sci. 34, 401-412. doi: 10.1016/j.tips.2013.05.002

Pallafacchina, G., Francois, S., Regnault, B., Czarny, B., Dive, V., Cumano, A., et al. (2010). An adult tissue-specific stem cell in its niche: a gene profiling analysis of in vivo quiescent and activated muscle satellite cells. Stem Cell Res. 4, 77-91. doi: 10.1016/j.scr.2009.10.003

Pannérec, A., Marazzi, G., and Sassoon, D. (2012). Stem cells in the hood: the skeletal muscle niche. Trends Mol. Med. 18, 599-606. doi: 10.1016/j.molmed.2012.07.004

Pantoja, M., Fischer, K. A., Ieronimakis, N., Reyes, M., and Ruohola-Baker, H. (2013). Genetic elevation of sphingosine 1-phosphate suppresses dystrophic muscle phenotypes in Drosophila. Development 140, 136-146. doi: 10.1242/dev.087791

Pedersen, B. K., and Febbraio, M. A. (2012). Muscles, exercise and obesity: skeletal muscle as a secretory organ. Nat. Rev. Endocrinol. 8, 457-465. doi: 10.1038/nrendo.2012.49

Pitson, S. M., Moretti, P. A., Zebol, J. R., Lynn, H. E., Xia, P., Vadas, M. A., et al. (2003). Activation of sphingosine kinase 1 by ERK1/2-mediated phosphorylation. EMBO J. 22, 5491-5500. doi: 10.1093/emboj/cdg540

Rapizzi, E., Donati, C., Cencetti, F., Nincheri, P., and Bruni, P. (2008). Sphingosine 1-phosphate differentially regulates proliferation of $\mathrm{C} 2 \mathrm{C} 12$ reserve cells and myoblasts. Mol. Cell. Biochem. 314, 193-199. doi: 10.1007/s11010-0089780-y

Rapizzi, E., Taddei, M. L., Fiaschi, T., Donati, C., Bruni, P., and Chiarugi, P. (2009). Sphingosine 1-phosphate increases glucose uptake through trans-activation of insulin receptor. Cell. Mol. Life Sci. 66, 3207-3218. doi: 10.1007/s00018-0090106-3

Ross, J. S., Hu, W., Rosen, B., Snider, A. J., Obeid, L. M., and Cowart, L. A. (2013). Sphingosine kinase 1 is regulated by PPARalpha in response to free fatty acids and is essential for skeletal muscle IL-6 production and signaling in diet-induced obesity. J. Biol. Chem. 288, 22193-22206. doi: 10.1074/jbc.M113.477786

Sampaolesi, M., Blot, S., D’Antona, G., Granger, N., Tonlorenzi, R., Innocenzi, A., et al. (2006). Mesoangioblast stem cells ameliorate muscle function in dystrophic dogs. Nature 444, 574-579. doi: 10.1038/nature05282

Sampaolesi, M., Torrente, Y., Innocenzi, A., Tonlorenzi, R., D’Antona, G., Pellegrino, M. A., et al. (2003). Cell therapy of alpha-sarcoglycan null dystrophic mice through intra-arterial delivery of mesoangioblasts. Science 301, 487-492. doi: $10.1126 /$ science. 1082254

Sato, K., Malchinkhuu, E., Horiuchi, Y., Mogi, C., Tomura, H., Tosaka, M., et al. (2007). Critical role of ABCA1 transporter in sphingosine 1-phosphate release from astrocytes. J. Neurochem. 103, 2610-2619. doi: 10.1111/j.14714159.2007.04958.x

Schiaffino, S., Dyar, K. A., Ciciliot, S., Blaauw, B., and Sandri, M. (2013). Mechanisms regulating skeletal muscle growth and atrophy. FEBS J. 280, 4294-4314. doi: 10.1111/febs.12253

Schnitzer, S. E., Weigert, A., Zhou, J., and Brune, B. (2009). Hypoxia enhances sphingosine kinase 2 activity and provokes sphingosine-1-phosphate-mediated chemoresistance in A549 lung cancer cells. Mol. Cancer Res. 7, 393-401. doi: 10.1158/1541-7786.MCR-08-0156

Shcherbata, H. R., Yatsenko, A. S., Patterson, L., Sood, V. D., Nudel, U., Yaffe, D., et al. (2007). Dissecting muscle and neuronal disorders in a Drosophila model of muscular dystrophy. EMBO J. 26, 481-493. doi: 10.1038/sj.emboj.7601503

Spiegel, S., and Milstien, S. (2003). Sphingosine-1-phosphate: an enigmatic signalling lipid. Nat. Rev. Mol. Cell Biol. 4, 397-407. doi: 10.1038/nrm1103

Squecco, R., Sassoli, C., Nuti, F., Martinesi, M., Chellini, F., Nosi, D., et al. (2006). Sphingosine 1-phosphateinduces myoblast differentiation through Cx43 pro- tein expression: a role for a gap junction-dependent and -independent function. Mol. Biol. Cell 17, 4896-4910. doi: 10.1091/mbc.E06-03-0243

Stahelin, R. V., Hwang, J. H., Kim, J. H., Park, Z. Y., Johnson, K. R., Obeid, L. M., et al. (2005). The mechanism of membrane targeting of human sphingosine kinase 1. J. Biol. Chem. 280, 43030-43038. doi: 10.1074/jbc.M507574200

Strub, G. M., Paillard, M., Liang, J., Gomez, L., Allegood, J. C., Hait, N. C., et al. (2011). Sphingosine-1-phosphate produced by sphingosine kinase 2 in mitochondria interacts with prohibitin 2 to regulate complex IV assembly and respiration. FASEB J. 25, 600-612. doi: 10.1096/fj.10-167502

Takabe, K., Kim, R. H., Allegood, J. C., Mitra, P., Ramachandran, S., Nagahashi, M., et al. (2010). Estradiol induces export of sphingosine 1-phosphate from breast cancer cells via ABCC1 and ABCG2. J. Biol. Chem. 285, 10477-10486. doi: 10.1074/jbc.M109.064162

Tedesco, F. S., Dellavalle, A., Diaz-Manera, J., Messina, G., and Cossu, G. (2010). Repairing skeletal muscle: regenerative potential of skeletal muscle stem cells. J. Clin. Invest. 120, 11-19. doi: 10.1172/JCI40373

Troy, A., Cadwallader, A. B., Fedorov, Y., Tyner, K., Tanaka, K. K., and Olwin, B. B. (2012). Coordination of satellite cell activation and self-renewal by Par-complex-dependent asymmetric activation of p38 $\alpha / \beta$ MAPK. Cell Stem Cell 11, 541-553. doi: 10.1016/j.stem. 2012.05.025

Xia, P., Wang, L., Moretti, P. A., Albanese, N., Chai, F., Pitson, S. M., et al. (2002). Sphingosine kinase interacts with TRAF2 and dissects tumor necrosis factoralpha signaling. J. Biol. Chem. 277, 7996-8003. doi: 10.1074/jbc.M111423200

Yaffe, D., and Saxel, O. (1977). Serial passaging and differentiation of myogenic cells isolated from dystrophic mouse muscle. Nature 270, 725-727. doi: $10.1038 / 270725 \mathrm{a} 0$

Yin, H., Price, F., and Rudnicki, M. A. (2013). Satellite cells and the muscle stem cell niche. Physiol. Rev. 93, 23-67. doi: 10.1152/physrev.00043.2011

Yoshida, N., Yoshida, S., Koishi, K., Masuda, K., and Nabeshima, Y. (1998). Cell heterogeneity upon myogenic differentiation: down-regulation of MyoD and Myf-5 generates 'reserve cells.' J. Cell Sci. 111(Pt 6), 769-779.

Zanin, M., Germinario, E., Dalla Libera, L., Sandona, D., Sabbadini, R. A., Betto, R., et al. (2008). Trophic action of sphingosine 1-phosphate in denervated rat soleus muscle. Am. J. Physiol. Cell Physiol. 294, C36-C46. doi: 10.1152/ajpcell.00164.2007

Zeidan, Y. H., and Hannun, Y. A. (2010). The acid sphingomyelinase/ceramide pathway: biomedical significance and mechanisms of regulation. Curr. Mol. Med. 10, 454-466. doi: 10.2174/156652410791608225

Conflict of Interest Statement: The authors declare that the research was conducted in the absence of any commercial or financial relationships that could be construed as a potential conflict of interest.

Received: 02 September 2013; accepted: 01 November 2013; published online: 25 November 2013.

Citation: Donati C, Cencetti F and Bruni P (2013) Sphingosine 1-phosphate axis: a new leader actor in skeletal muscle biology. Front. Physiol. 4:338. doi: 10.3389/fphys. 2013.00338

This article was submitted to Striated Muscle Physiology, a section of the journal Frontiers in Physiology.

Copyright (1) 2013 Donati, Cencetti and Bruni. This is an open-access article distributed under the terms of the Creative Commons Attribution License (CC BY). The use, distribution or reproduction in other forums is permitted, provided the original author(s) or licensor are credited and that the original publication in this journal is cited, in accordance with accepted academic practice. No use, distribution or reproduction is permitted which does not comply with these terms. 